\title{
Fusarium Root and Crown Rot: A Disease of Container-Grown Hostas
}

\author{
B. Wang and S. N. Jeffers, Department of Plant Pathology and Physiology, Clemson University, Clemson, SC \\ 29634-0377
}

\begin{abstract}
Wang, B., and Jeffers, S. N. 2000. Fusarium root and crown rot: A disease of container-grown hostas. Plant Dis. 84:980-988.

A previously unreported disease was observed on 11 cultivars of container-grown hosta plants at five wholesale nurseries in South Carolina between 1997 and 1999. Symptoms included leaf yellowing, plant stunting, rotting of and vascular discoloration in roots, and necrosis in the crowns. Fusarium spp. consistently were isolated from symptomatic hosta plants. Four species were recovered: $F$. solani, $F$. oxysporum, $F$. proliferatum, and an undescribed species designated Fusarium sp.; F. solani and Fusarium sp. were recovered most frequently. To demonstrate pathogenicity, four methods were used to inoculate hosta plants with representative isolates of $F$. solani, F. oxysporum, and Fusarium sp. Two types of inoculum, colonized oat seeds and conidium suspensions, were used to inoculate wounded and nonwounded plants. Disease symptoms occurred consistently only on hosta plants inoculated by dipping wounded roots and crowns into suspensions of conidia. Symptoms were most severe on plants inoculated with Fusarium sp. and much less severe on plants inoculated with $F$. solani or $F$. oxysporum. Disease severity increased and fresh weight of inoculated plants decreased when the concentration of inoculum of Fusarium sp. was increased over the range of $1 \times 10^{3}$ to $1 \times 10^{7}$ conidia per ml. Isolates of Fusarium sp., F. solani, and F. oxysporum varied in virulence when Hosta 'Francee' plants were inoculated. This study demonstrated that Fusarium root and crown rot of container-grown hostas is caused primarily by Fusarium sp. but that it also can be caused by $F$. solani and F. oxysporum. Fusarium sp. appears to be taxonomically distinct from other species, and its identity currently is under investigation.
\end{abstract}

Hosta, also known as plantain lily or funkia, is in the family Liliaceae and is comprised of over 100 species and subspecific taxa and a multitude of registered and unregistered cultivars (29). It is well adapted to many landscape settings as well as most geographical regions in the United States and is one of the most popular herbaceous perennials planted in landscapes around the country (29). Consequently, hostas are grown extensively in ornamental crop nurseries, and many nurseries in South Carolina and throughout the Southeast are increasing production of this popular perennial crop. In South Carolina alone, some nurseries have hundreds of thousands of containergrown hostas in nursery beds at all stages of development. The wholesale price for hostas in South Carolina in 2000 varied

Corresponding author: S. N. Jeffers

E-mail: sjffrs@clemson.edu

This research was supported in part by a grant (SC001749) from the Clemson University Program for Enhancement of Research and Extension in Ornamental Horticulture.

Technical contribution 4586 of the South Carolina Agriculture and Forestry Research System, Clemson University.

Accepted for publication 26 May 2000.

Publication no. D-2000-0627-02R

(C) 2000 The American Phytopathological Society from $\$ 2.50$ to $\$ 15.00$ per plant, depending on cultivar and container size. Although it is not possible to put a dollar value on hosta production exclusively because this is only one of many crops grown in ornamental crop nurseries, it is safe to say that hosta production has become "big business" for many of these nurseries. stunted due to disease development.
One reason hostas are popular is that they are relatively free of problems, including those caused by insects and diseases (29). In fact, only a few diseases of hostas have been reported $(10,22,29)$. However, large-scale production of hostas and other ornamental crops in nurseries can increase the development of diseases and insect pests that usually are not problems in the landscape (S. N. Jeffers, personal observation). Because of the importance of the hosta crop to the nursery industry in South Carolina and the Southeast, economically important disease problems on container-grown hostas are a primary concern.

A root and crown rot disease was observed on container-grown hosta plants at a large wholesale production nursery in South Carolina in 1997. Up to $10 \%$ of the plants growing in the nursery were affected, and thousands of plants were discarded. The disease caused uneven shoot emergence and serious decline of the plants-particularly after plants had been cut back and divided to increase plant numbers (Fig. 1). Typical symptoms were the following: leaves turned yellow and then tan and withered; roots had cortical decay distal to the crown and discoloration of the vascular stele proximal to the crown; crowns had pockets of necrosis that varied in size; and, overall, plants were stunted and declining (Fig. 2). In preliminary in-

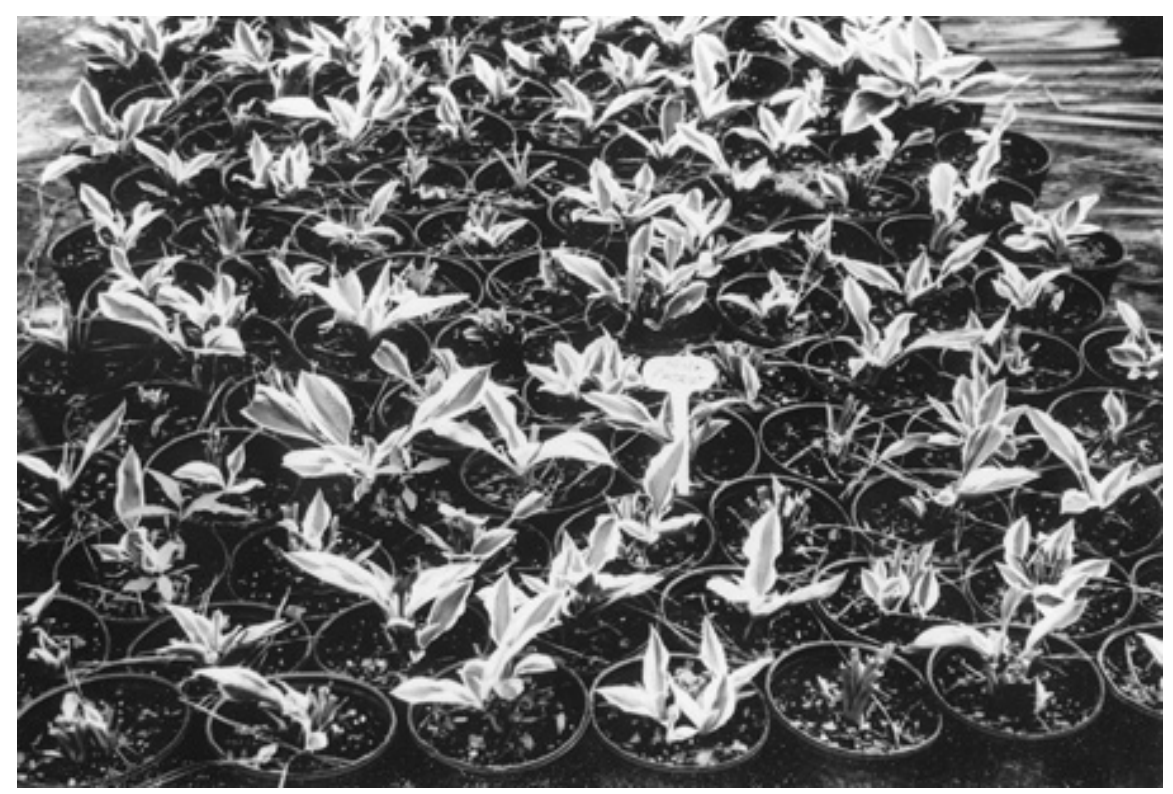

Fig. 1. Symptoms of Fusarium root and crown rot on hosta plants (Hosta 'Patriot') in a nursery. These plants recently were divided and transplanted; shoot emergence is uneven and plants are 
vestigations, Fusarium spp. consistently were isolated from symptomatic plants using several nonselective agar media, including acidified potato dextrose agar and water agar.

Fusarium spp. are common soilborne plant pathogens of numerous agricultural crops, including many ornamental plants $(3,10)$. They cause a variety of diseases, including rots of roots, root crowns, stems, and underground storage organs such as bulbs, corms, and tubers; vascular wilts; and postharvest decay. Root and crown rots caused by Fusarium spp. are not uncommon and have been reported on many crops, such as tomato (13), asparagus (9), alfalfa (16), sainfoin (15), sweet basil (12), birdsfoot trefoil (1), and some others (4,27,28,31). Although Fusarium spp. have been reported to attack other species in the family Liliaceae (10) (e.g., onion, asparagus, daylily, hyacinth, liriope, narcissus, tulip, and various lilies), there is no confirmed report of a species of Fusarium causing a disease of hosta.

The primary objectives of our study were to determine the etiology and distribution of this previously unreported root and crown rot of hosta. We also evaluated the effectiveness of different inoculation methods, the effect of inoculum concentra- tion, and variation in virulence among isolates. Preliminary results have been reported $(33,34)$.

\section{MATERIALS AND METHODS}

Isolation of fungi. Initially, this disease was observed in 1997 at one wholesale nursery (designated nursery A) in South Carolina. In October 1998, 15 symptomatic plants representing six cultivars (Hosta 'Fortunei Albomarginata', 7 plants; $H$. 'Gold Standard', 2 plants; $H$. 'Minute Man', 2 plants; $H$. 'Wide Brim', 2 plants; $H$. 'Great Expectations', 1 plant; $H$. 'Francee', 1 plant) were collected. Roots and crowns were washed in running tap water to remove attached debris and then rinsed twice in sterile distilled water. Three to five pieces (approximately $10 \times 1 \times 1$ $\mathrm{mm}$ ) were cut from the discolored vascular tissue of roots and the necrotic tissue of crowns from each plant, and each piece of tissue was placed on an agar medium in a standard disposable petri plate $(100 \times 15$ $\mathrm{mm})$. Because Fusarium spp. were suspected based on preliminary investigations, two media that favored growth of these fungi were used: modified Nash-Snyder medium (25) and potato dextrose agar (PDA; Difco Laboratories, Detroit, MI) amended with $750 \mathrm{mg}$ of pentachloronitro- benzene (PCNB) as Terraclor 75WP (Uniroyal Chemical Co., Middlebury, CT) and $300 \mathrm{mg}$ of streptomycin sulfate (Sigma Chemical Co., St. Louis, MO) per liter. Isolation plates were placed in an incubator $\left(14 \mathrm{~h}\right.$ of light at $25^{\circ} \mathrm{C}$ and $10 \mathrm{~h}$ of dark at $20^{\circ} \mathrm{C}$; the photoperiod was provided by two $115 \mathrm{~W}$ cool-white fluorescent tubes [Sylvania F48T12/CW/VHO]) for 1 week. This incubator and these settings were used routinely throughout the study. All colonies suspected to be Fusarium spp. were subcultured on one-quarter strength PDA ( $1 / 4 \mathrm{PDA})$; eventually, single-spore colonies of representative isolates from each plant were produced, subcultured, and stored on $1 / 4 \mathrm{PDA}$ in glass, screw-cap vials at $4^{\circ} \mathrm{C}$ in the dark. Some isolates were transferred to wet, sterilized filter paper disks $(55 \mathrm{~mm}$ in diameter) and grown for 10 days in the incubator. Disks were allowed to air-dry completely in the incubator for 2 to 3 weeks and then were cut into small pieces. Pieces were put into sterilized glass, screw-cap vials $(7.4 \mathrm{ml}[2 \mathrm{dram}])$, and vials were stored indefinitely at $4{ }^{\circ} \mathrm{C}$ in the dark.

Disease distribution. In 1998 and 1999, five additional wholesale nurseries that produced large quantities of hostas in containers were surveyed (designated nurseries

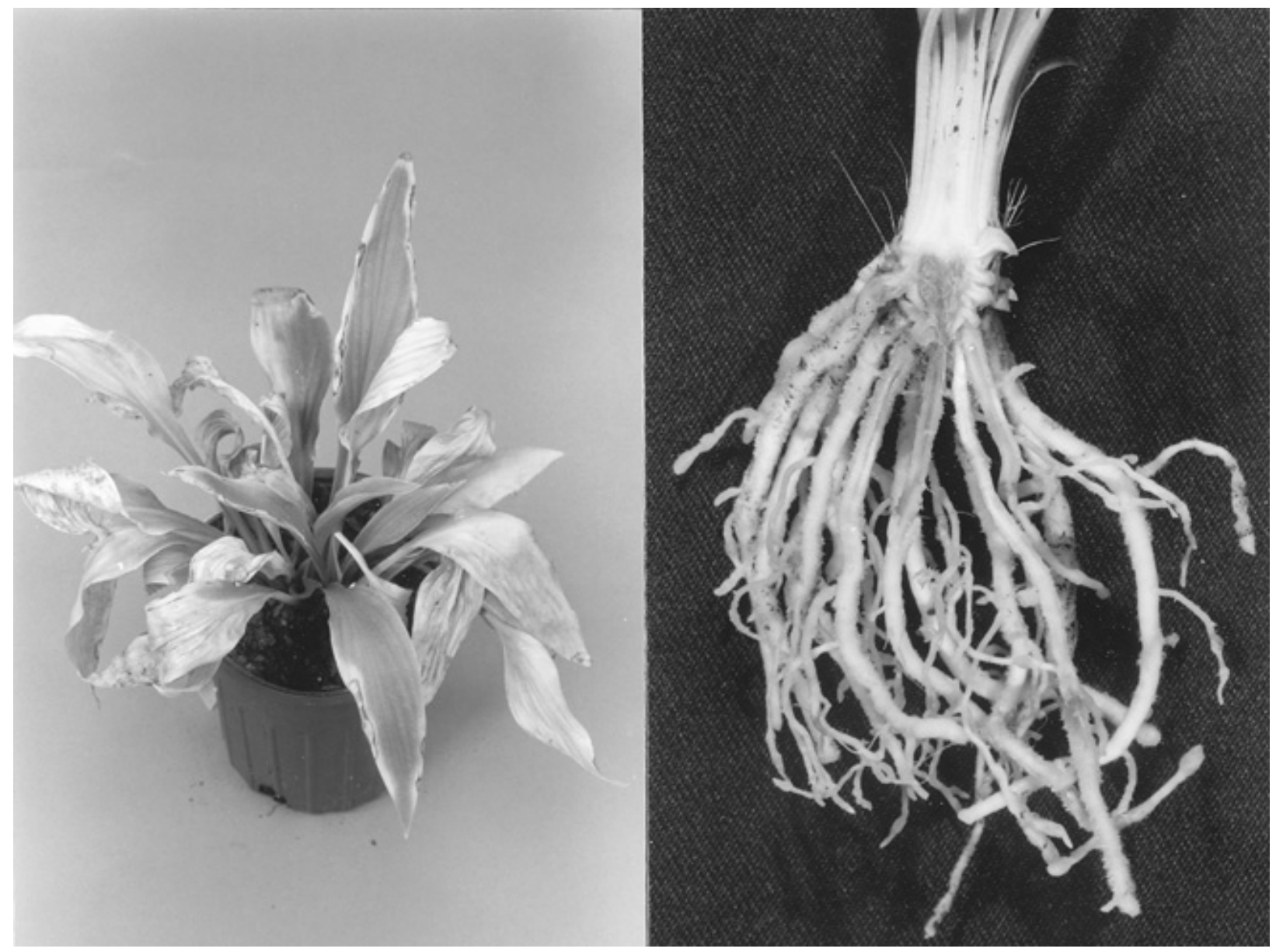

Fig. 2. Symptoms of Fusarium root and crown rot on a single hosta plant (Hosta 'Fortunei Albopicta'): aboveground, leaves turn yellow, become necrotic, and wither (left); belowground, brown necrosis occurs in the crown and in vascular steles of roots near the crown, and an overall rotting of the roots occurs away from the crown (right). 
$\mathrm{B}, \mathrm{C}, \mathrm{D}, \mathrm{E}$, and F) to determine the distribution of Fusarium root and crown rot. Hosta plants were examined for the foliar symptoms described previously. Suspect plants were removed from containers, and roots and crowns were cut open to look for necrosis and vascular discoloration. In all, 47 symptomatic plants were brought to the laboratory for examination, where isolations were conducted from symptomatic roots and crowns as described previously.

Identification of Fusarium spp. Isolates were grown on both carnation leaf agar (11) and PDA made from fresh potatoes (decoction from $200 \mathrm{~g}$ of potatoes, 20 $\mathrm{g}$ of glucose, and $15 \mathrm{~g}$ of Bacto agar [Difco] per liter) in the incubator until sporodochia were produced abundantly (usually 7 to 10 days). Isolates then were identified according to the classification system of Nelson et al. (25) based on the morphological characteristics of colonies, microconidia, macroconidia, and conidiophores. Representative isolates of identified species and isolates that did not conform to described species were sent to D. M. Geiser at the Fusarium Research Center (Pennsylvania State University, University Park) for confirmation and additional examination.

Pathogenicity of Fusarium spp. Hosta plants were inoculated with representative isolates of three species of Fusarium to determine pathogenicity. Four isolates each of F. solani, F. oxysporum, and Fusarium sp. were pooled together to make a composite inoculum for each species. All isolates were obtained from nursery A.

To determine the most effective procedure to inoculate plants, four inoculation methods were evaluated, which included two forms of inoculum (colonized oat seeds and conidium suspensions) and two root and crown conditions (nonwounded and wounded). To prepare colonized oat seeds, $20-\mathrm{cm}^{3}$ aliquots, each containing approximately 150 oat seeds, were placed in 50-ml Erlenmeyer flasks; seeds were soaked in tap water overnight, drained, and then autoclaved twice-once on each of two consecutive days. Each flask was seeded with agar plugs of one isolate, and all flasks were maintained in the incubator until seeds were completely colonized (about 3 weeks). Colonized seeds then were removed from the flasks and air-dried completely at room temperature (22 to $24^{\circ} \mathrm{C}$ ), which took approximately 10 days. To prepare conidium suspensions, isolates were grown for 1 week in $125 \mathrm{ml}$ of potato dextrose broth (PDB; Difco) in 250-ml Erlenmeyer flasks on an orbital shaker at $150 \mathrm{rpm}$ at room temperature. Cultures then were poured through four layers of cheese cloth to remove fragments of hyphae. Conidium suspensions were standardized to $5 \times 10^{6}$ conidia per $\mathrm{ml}$ by diluting culture filtrates with sterile distilled water. The four isolates of each species were combined to make pooled conidium suspensions. The $\mathrm{pH}$ values of conidium suspensions were adjusted to 5.0 with 0.05 $\mathrm{N} \mathrm{HCl}$.

To test for pathogenicity on plants with roots and crowns that were not wounded, single hosta plants were transplanted into fresh container mix $(75 \%$ bark and $25 \%$ peat) (Nursery Mix; Fafard, Inc., Anderson, SC) in $15-\mathrm{cm}$ square plastic pots and grown for 2 weeks in a walk-in growth chamber before inoculation. Four holes then were made in the container mix around each plant; holes were $3 \mathrm{~mm}$ in diameter, $15 \mathrm{~mm}$ deep, and $20 \mathrm{~mm}$ away from and evenly distributed around the plant. To inoculate the plants, either one colonized oat seed was placed or $2.5 \mathrm{ml}$ of conidium suspension was pipetted into each of the four holes. When colonized oat seeds were used, each of the four holes in a pot received a different isolate of a given species.

To test for pathogenicity on plants with wounded roots and crowns, hosta plants were removed from pots, container mix debris was gently removed from the roots and crowns, and then roots were severed completely with scissors $5 \mathrm{~cm}$ from the rhizome and crowns were wounded with a scalpel by making two 2-mm-deep incisions perpendicular to each other. Wounded plants were inoculated either by transplanting directly into fresh container mix in $15-\mathrm{cm}$ square plastic pots that had been uniformly infested with ground colonized oat seeds (using 40 seeds per pot, 10 seeds of each isolate) or by dipping wounded roots and crowns into a pooled conidium suspension for $5 \mathrm{~min}$ and then transplanting into fresh, uninfested container mix in $15-\mathrm{cm}$ square plastic pots. Therefore, the four inoculation methods were: nonwounded plants grown in container mix infested with intact colonized oat seeds, nonwounded plants grown in mix infested with a conidium suspension, wounded plants grown in mix infested with ground colonized oat seeds, and wounded plants dipped in conidium suspension and then grown in uninfested container mix. For the control treatments, plants were treated similarly using uncolonized oat seeds or distilled water in each inoculation method. In all, there were 16 treatments: four inoculation methods for each of three fungus inocula and the controls.

Each treatment was replicated on five plants, and the experiment was conducted twice. In the first trial, nursery-grown $H$. 'Fortunei Albomarginata' plants were inoculated; in the second trial, $H$. 'Francee' plants were grown from plugs produced in tissue culture (Agri-Starts III, Inc., Eustis, FL) and then were inoculated. Plants were grown in a walk-in growth chamber (20 to $22^{\circ} \mathrm{C}$ with a 14 -h photoperiod and a light intensity of $50 \mu \mathrm{E} \cdot \mathrm{s}^{-1} \cdot \mathrm{m}^{-2}$ ) for 5 weeks after plants were inoculated. To reisolate pathogens at the end of the trials, tissue pieces were cut aseptically from symptomatic roots or crowns, surface-disinfested in $0.5 \% \mathrm{NaOCl}$ solution for $1 \mathrm{~min}$, and placed onto $1 / 4$ PDA. Plates were held in the incubator for 1 week, and colonies of Fusarium spp. were subcultured and identified.

Effect of inoculum concentration on disease development. Two isolates of Fusarium sp., F12 and F46, were used to determine the effect of inoculum concentration on disease severity. A concentrated conidium suspension of each isolate was prepared as described previously. These suspensions were diluted with sterile distilled water to produce five conidium concentrations for evaluation: $1 \times 10^{3}, 1 \times 10^{4}$, $1 \times 10^{5}, 1 \times 10^{6}$, and $1 \times 10^{7}$ conidia per $\mathrm{ml}$. Roots and crowns of $H$. 'Francee' plants were wounded and dipped into inocula, and then plants were transplanted and grown in the growth chamber, as described previously. This 2 (isolates) $\times 5$ (conidium concentrations) factorial experiment had eight replicate plants per treatment and was conducted twice.

Variation in virulence among isolates of Fusarium spp. Relative virulence among isolates of the three species of Fusarium recovered most frequently from diseased hosta plants was evaluated using $H$. 'Francee' plants grown from tissue culture plugs. Plants were inoculated by dipping wounded roots and crowns into conidium suspensions $\left(1 \times 10^{6}\right.$ conidia per $\left.\mathrm{ml}\right)$ of each isolate following the procedures described previously. In the first experiment, 13 isolates of Fusarium sp. from nursery $\mathrm{A}$ and a noninoculated control treatment were compared. Eight replicate plants were used for each treatment, and the experiment was conducted twice. In the second experiment, 13 additional isolates of Fusarium sp. (12 from nursery $\mathrm{C}$ and 1 from nursery D) and a noninoculated control treatment were compared. This experiment was conducted twice, using five replicates per treatment in one trial and four replicates per treatment in the other trial. In the third experiment, five isolates each of $F$. solani and $F$. oxysporum from nursery $\mathrm{A}$ and a noninoculated control treatment were compared using six replicates per treatment; this experiment also was conducted twice.

Treatment assessment and data analysis. In all experiments, plants were harvested 5 weeks after inoculation. They were removed from pots, and roots and crowns were gently washed free of container mix, blotted with paper towels, and air-dried at room temperature $\left(22\right.$ to $\left.24^{\circ} \mathrm{C}\right)$ for $30 \mathrm{~min}$ to remove excess moisture. Individual plants were cut into two parts at the soil line, roots and shoots, and fresh weights of roots, shoots, and whole plants were measured to determine the effect of the pathogens on plant growth and development. In addition, disease severity was assessed by cutting the plants longitudinally through the roots and crown and rating symptom development on a scale of 
0 to 5 , where $0=$ no discoloration, $1=$ slight discoloration of vascular tissue in roots, $2=$ extensive discoloration of vascular tissue in roots, $3=$ slight discoloration of vascular tissue and cortex in the crown, $4=$ extensive discoloration of vascular tissue and cortex in the crown, and 5 = crown completely necrotic. This rating scale was adopted from a similar scale used for another crop (7).

Data were analyzed by one- and twoway analyses of variance (ANOVA) using MINITAB Release 12.2 for Windows (Minitab Inc., State College, PA). Whenever possible, data from repeated trials of individual experiments were combined for analysis based on the results from tests for homogeneity of variance. Treatments means were compared using Fisher's pro- tected least significant difference (LSD) with $P=0.05$. In two-way ANOVAs, means from individual treatments were compared if interactions were significant $(P \leq 0.05)$. When interactions were not significant $(P>0.05)$, individual treatments were combined to evaluate effects of treatments in the two main factors.

\section{RESULTS}

Identification and incidence of Fusarium spp. Fusarium spp. were detected in all of the 15 diseased plants from nursery A, the nursery where root and crown rot was first observed. In all, four species were recovered: F. solani, F. oxysporum, F proliferatum, and a species of Fusarium that did not match any of the described species, which will be referred to as Fusarium sp.

Table 1. Incidence of Fusarium spp. on 15 hosta plants with root and crown rot symptoms from six cultivars at one nursery in $1998^{\mathrm{x}}$

\begin{tabular}{lcccc}
\hline & \multicolumn{3}{c}{ Plants (no.) $^{\mathbf{y}}$} & \\
\cline { 2 - 4 } Species & Roots & Crowns & Total & Cultivars (no.) $^{\mathbf{z}}$ \\
\hline F. solani & 9 & 7 & 11 & 5 \\
Fusarium sp. & 0 & 9 & 9 & 3 \\
F. oxysporum & 3 & 6 & 7 & 4 \\
F. proliferatum & 0 & 1 & 1 & 1
\end{tabular}

${ }^{\mathrm{x}}$ Number of symptomatic plants sampled of each cultivar: 7 Hosta 'Fortunei Albomarginata', $2 \mathrm{H}$. 'Gold Standard', $2 \mathrm{H}$. 'Minute Man', $2 \mathrm{H}$. 'Wide Brim', $1 \mathrm{H}$. 'Francee', and $1 \mathrm{H}$. 'Great Expectations'.

${ }^{y}$ Number of plants from which Fusarium spp. were isolated from roots, crowns, or either roots or crowns (total).

${ }^{\mathrm{z}}$ Number of cultivars from which Fusarium spp. were isolated.
This undescribed species has been investigated thoroughly at the Fusarium Research Center and has been determined to be distinct from other species of Fusarium based on morphological and molecular analyses (D. M. Geiser, personal communication). Therefore, it tentatively has been named Fusarium hostae Geiser \& Juba, sp. nov., pending appropriate publication of taxonomic criteria (a manuscript has been submitted). $F$. hostae resembles $F$. oxysporum by producing abundant chlamydospores, short monophialides, and highly branched conidiophores. However, it differs from $F$. oxysporum by producing stout macroconidia, chlamydospores in chains, and polyphialides as well as monophialides. In addition, one isolate produced perithecia, which suggests that the teleomorph is homothallic. $F$. hostae more closely resembles $F$. redolens, which produces chlamydospores in chains but no polyphialides; however, molecular analyses, growth on agar media, and sexual capability clearly demonstrated that these two species are distinct.

Three of the four species were recovered from at least $45 \%$ of the plants and $50 \%$ of the cultivars sampled (Table 1). F. solani and Fusarium sp. were recovered most frequently-from 73 and $60 \%$ of the plants, respectively; $F$. oxysporum was recovered from $47 \%$ of the plants; and $F$. proliferatum was recovered from only one plant. F. solani and F. oxysporum were

Table 2. Incidence of Fusarium spp. on 47 hosta plants with root and crown rot symptoms from 11 cultivars at six nurseries in South Carolina in 1998 and 1999

\begin{tabular}{|c|c|c|c|c|c|c|}
\hline \multirow[b]{2}{*}{ Nursery } & \multicolumn{2}{|c|}{ Plants sampled $^{\mathrm{v}}$} & \multicolumn{4}{|c|}{ No. of plantsw } \\
\hline & Cultivar & No. & Fusarium sp. & F. solani & F. oxysporum & F. proliferatum \\
\hline \multirow[t]{7}{*}{ A } & $H$. 'Fortunei Albomarginata' & 7 & 6 & 5 & 3 & 0 \\
\hline & H. 'Gold Standard' & 2 & 2 & 2 & 0 & 0 \\
\hline & H. 'Minute Man' & 2 & 0 & 1 & 1 & 0 \\
\hline & $H$. 'Wide Brim' & 2 & 0 & 2 & 2 & 1 \\
\hline & H. 'Francee' & 1 & 0 & 1 & 1 & 0 \\
\hline & $H$. 'Great Expectations' & 1 & 1 & 0 & 0 & 0 \\
\hline & All cultivars & 15 & 9 & 11 & 7 & 1 \\
\hline \multirow[t]{3}{*}{ B } & $H$. 'Great Expectations' & 4 & 0 & 3 & 1 & 2 \\
\hline & $H$. 'Wide Brim' & 3 & 0 & 3 & 0 & 0 \\
\hline & All cultivars & 7 & 0 & 6 & 1 & 2 \\
\hline \multirow[t]{4}{*}{$\mathrm{C}$} & H. 'Fortunei Albopicta' & 8 & 7 & 1 & 0 & 0 \\
\hline & H. 'Fortunei Aureomarginata' & 7 & 5 & 3 & 0 & 0 \\
\hline & H. 'Gold Standard' & 6 & 0 & 5 & 0 & 0 \\
\hline & All cultivars & 21 & 12 & 9 & 0 & 0 \\
\hline \multirow[t]{3}{*}{$\mathrm{D}$} & H. 'Halcyon' & 1 & 0 & 1 & 0 & 0 \\
\hline & $H$. 'Wide Brim' & 1 & 1 & 0 & 0 & 0 \\
\hline & All cultivars & 2 & 1 & 1 & 0 & 0 \\
\hline \multirow[t]{3}{*}{$\mathrm{E}$} & $H$. 'Frances Williams' & 1 & 1 & 0 & 0 & 0 \\
\hline & Unknown $^{\mathrm{x}}$ & 1 & 1 & 1 & 0 & 0 \\
\hline & All cultivars & 2 & 2 & 1 & 0 & 0 \\
\hline \multirow{2}{*}{\multicolumn{7}{|c|}{$\begin{array}{l}\mathrm{F} \\
\text { Totals }^{\mathrm{z}}\end{array}$}} \\
\hline & & & & & & \\
\hline & 4 & 5 & 2 & 2 \\
\hline \multirow{2}{*}{\multicolumn{3}{|c|}{$\begin{array}{l}\text { No. of cultivars } \\
\text { No. (and percentage) of plants }\end{array}$}} & 8 & 10 & 5 & 2 \\
\hline & & & $24(51 \%)$ & $28(60 \%)$ & $8(17 \%)$ & $3(6 \%)$ \\
\hline
\end{tabular}

${ }^{\mathrm{v}}$ Different cultivars and number of symptomatic plants in each cultivar that were sampled at the six nurseries.

${ }^{\text {w }}$ Number of plants from which each species of Fusarium was isolated.

${ }^{x}$ Name of this cultivar was not known.

y No symptomatic plants were found at this nursery.

${ }^{\mathrm{z}}$ Total number of nurseries, cultivars, and plants from which each species was isolated. 
isolated from both roots and crowns, but Fusarium sp. and $F$. proliferatum were isolated only from the crowns of diseased plants (Table 1). Frequently, multiple species of Fusarium were isolated from the same plant. We isolated one species of Fusarium from five plants, two species from seven plants, and three species from three plants. Of the 15 symptomatic plants sampled, F. solani and Fusarium sp. occurred together in seven plants (five $H$. 'Fortunei Albomarginata' and two $H$. 'Gold Standard').

Disease distribution. In 1998 and 1999, a total of six large-scale wholesale nurseries that produced hostas in containers were surveyed for Fusarium root and crown rot, including the nursery where the disease was first observed (Table 2); the disease was found at five of these nurseries. In all, 47 symptomatic plants representing 11 cultivars were collected and brought back to the laboratory, and Fusarium spp. were isolated from all of these plants. $F$. solani and Fusarium sp. were recovered most frequently-from 60 and $51 \%$ of the plants, respectively, and at five and four nurseries, respectively. The other two spe- cies were recovered infrequently; $F$. oxysporum and $F$. proliferatum were isolated from 9 and 3\%, respectively, of all plants collected and were found at only two of the nurseries.

Pathogenicity of Fusarium spp. Four methods were used to inoculate hosta plants with pooled inocula of three species of Fusarium-Fusarium sp., F. solani, and $F$. oxysporum. $F$. proliferatum was not tested for pathogenicity because it was recovered so infrequently from symptomatic plants. In two-way ANOVAs for disease severity, the interaction between species and inoculation method was highly significant on both hosta cultivars (Table 3), so individual treatments (i.e., each combination of a species and an inoculation method) were compared. Based on disease severity ratings, only Fusarium sp. caused significant disease on both $H$. 'Fortunei Albomarginata' and $H$. 'Francee', and only when plants were inoculated by dipping wounded roots and crowns into a conidium suspension (Table 3 ). In fact, Fusarium sp. was the only species to cause significant disease on $H$. 'Francee'. On $H$. 'Fortunei Albomarginata', disease severity was greatest when wounded plants were inoculated with conidia of Fusarium sp.; however, disease severity also was significantly greater than that on the noninoculated control plants when wounded plants were inoculated with conidium suspensions of both $F$. solani and $F$. oxysporum. Fusarium sp. was the only species to cause significant disease symptoms on nonwounded plants grown in container mix infested with conidia. Only Fusarium sp. was reisolated consistently from inoculated plants.

Throughout this study, fresh weight of whole plants was the most consistent and uniform parameter for determining the effect of Fusarium spp. on plant growth. In the experiment to determine pathogenicity, the interaction between species of Fusarium and inoculation method did not have a significant effect on plant weight for either cultivar, so the main effects of species and inoculation method could be evaluated (Table 3). On the two different cultivars, there was no significant effect associated with species, but there was a significant effect associated with inoculation method. Plants in all treatments

Table 3. Pathogenicity of Fusarium spp. to Hosta 'Fortunei Albomarginata' in one trial and to $H$. 'Francee' in another trial using four inoculation methods ${ }^{t}$

\begin{tabular}{|c|c|c|c|c|c|c|}
\hline \multirow[b]{2}{*}{ Species $^{v}$} & \multicolumn{2}{|c|}{ Inoculation method ${ }^{u}$} & \multicolumn{2}{|c|}{ Albomarginata } & \multicolumn{2}{|c|}{ Francee } \\
\hline & Inoculum & Wounding & Disease severity $^{w}$ & Plant wt. $(g)^{x}$ & Disease severity $^{w}$ & Plant wt. $(g)^{\mathrm{x}}$ \\
\hline F. solani & $\begin{array}{l}\text { Seeds } \\
\text { Seeds } \\
\text { Conidia } \\
\text { Conidia }\end{array}$ & $\begin{array}{l}- \\
+ \\
- \\
+\end{array}$ & $\begin{array}{l}0 \mathrm{c} \\
0 \mathrm{c} \\
0 \mathrm{c} \\
1.2 \mathrm{~b}\end{array}$ & $\begin{array}{l}54.8 \\
31.0 \\
61.2 \\
42.8\end{array}$ & $\begin{array}{l}0 \mathrm{~b} \\
0 \mathrm{~b} \\
0 \mathrm{~b} \\
0 \mathrm{~b}\end{array}$ & $\begin{array}{l}16.0 \\
13.3 \\
12.3 \\
12.6\end{array}$ \\
\hline Fusarium sp. & $\begin{array}{l}\text { Seeds } \\
\text { Seeds } \\
\text { Conidia } \\
\text { Conidia }\end{array}$ & $\begin{array}{l}- \\
+ \\
- \\
+\end{array}$ & $\begin{array}{l}0 \mathrm{c} \\
0 \mathrm{c} \\
1.2 \mathrm{~b} \\
3.2 \mathrm{a}\end{array}$ & $\begin{array}{l}60.9 \\
39.1 \\
63.1 \\
34.2\end{array}$ & $\begin{array}{l}0 \mathrm{~b} \\
0 \mathrm{~b} \\
0 \mathrm{~b} \\
2.4 \mathrm{a}\end{array}$ & $\begin{array}{l}14.1 \\
13.6 \\
15.9 \\
10.5\end{array}$ \\
\hline F. oxysporum & $\begin{array}{l}\text { Seeds } \\
\text { Seeds } \\
\text { Conidia } \\
\text { Conidia }\end{array}$ & $\begin{array}{l}- \\
+ \\
- \\
+\end{array}$ & $\begin{array}{l}0 \mathrm{c} \\
0 \mathrm{c} \\
0.8 \mathrm{bc} \\
1.0 \mathrm{~b}\end{array}$ & $\begin{array}{l}53.3 \\
31.4 \\
49.2 \\
36.8\end{array}$ & $\begin{array}{l}0 \mathrm{~b} \\
0 \mathrm{~b} \\
0.2 \mathrm{~b} \\
0.2 \mathrm{~b}\end{array}$ & $\begin{array}{r}15.2 \\
9.2 \\
12.7 \\
7.1\end{array}$ \\
\hline Control & $\begin{array}{l}\text { Seeds } \\
\text { Seeds } \\
\text { Conidia } \\
\text { Conidia }\end{array}$ & $\begin{array}{l}- \\
+ \\
- \\
+\end{array}$ & $\begin{array}{l}0 \mathrm{c} \\
0 \mathrm{c} \\
0 \mathrm{c} \\
0 \mathrm{c}\end{array}$ & $\begin{array}{l}55.4 \\
33.1 \\
56.6 \\
23.7\end{array}$ & $\begin{array}{l}0 \mathrm{~b} \\
0 \mathrm{~b} \\
0 \mathrm{~b} \\
0 \mathrm{~b}\end{array}$ & $\begin{array}{r}14.9 \\
9.9 \\
17.1 \\
11.4\end{array}$ \\
\hline $\begin{array}{l}\text { Inoculation method: } \\
\text { Main effect }{ }^{\mathrm{y}}\end{array}$ & $\begin{array}{l}\text { Seeds / - wounding } \\
\text { Seeds / + wounding } \\
\text { Conidia / - wounding } \\
\text { Conidia / + wounding }\end{array}$ & & & $\begin{array}{l}56.3 \mathrm{a} \\
32.5 \mathrm{~b} \\
58.6 \mathrm{a} \\
34.4 \mathrm{~b}\end{array}$ & & $\begin{array}{r}15.7 \mathrm{a} \\
11.2 \mathrm{~b} \\
14.7 \mathrm{a} \\
9.5 \mathrm{~b}\end{array}$ \\
\hline $\begin{array}{l}\text { Two-way ANOVA- } \\
\text { Species main effect } \\
\text { Inoculation method } \\
\text { Species } \times \text { inoculati } \\
\text { LSD }(P=0.05)^{\mathrm{z}}\end{array}$ & $\begin{array}{l}\text { lues } \\
\text { effect } \\
\text { thod interaction }\end{array}$ & & $\begin{array}{c}<0.001 \\
<0.001 \\
<0.001 \\
0.83\end{array}$ & $\begin{array}{c}0.576 \\
<0.001 \\
0.933 \\
9.04\end{array}$ & $\begin{array}{c}<0.001 \\
<0.001 \\
<0.001 \\
0.33\end{array}$ & $\begin{array}{c}0.321 \\
<0.001 \\
0.239 \\
2.43\end{array}$ \\
\hline
\end{tabular}

${ }^{\mathrm{t}}$ In each trial, five replicate plants were used for each treatment, and plants were grown in $15-\mathrm{cm}$, square plastic pots in a growth room at 20 to $22^{\circ} \mathrm{C}$ for 5 weeks after inoculation.

" The four inoculation methods involved two types of inocula, colonized oat seeds and conidium suspensions, and plants with nonwo unded or wounded roots and crowns.

${ }^{v}$ For each species, four isolates were pooled to prepare a composite inoculum.

${ }^{\mathrm{w}}$ Disease severity was based on symptom development in the roots and crown using a scale of 0 to $5: 0=$ no discoloration; $1=$ slight discoloration of vascular tissue in roots, $2=$ extensive discoloration of vascular tissue in roots, $3=$ slight discoloration of vascular tissue and cortex in the crown, $4=$ extensive discoloration of vascular tissue and cortex in the crown, and $5=$ crown completely necrotic. Within each column, means without a letter in common are significantly different based on Fisher's protected least significant difference (LSD; $P=0.05$ ).

${ }^{x}$ Plant weight is the fresh weight of whole plants. Within each column, means for the main effect of inoculation method without a letter in common are significantly different based on Fisher's protected LSD $(P=0.05)$.

${ }^{y}$ In the two-way analysis of variance (ANOVA), the only significant effect was the main effect of inoculation method on plant weight. These means are for all species of Fusarium combined.

${ }^{\mathrm{z}}$ Least significant difference values are based on the interaction for disease severity and on main effect of inoculation method for plant weight. 
(including the noninoculated control) that had been wounded weighed less than those that were not wounded regardless of the type of inoculum used.

Effect of inoculum concentration on disease development. The effect of inoculum concentration of Fusarium sp. was determined using two isolates and five conidium concentrations, and two trials were conducted. Variances associated with disease severity in the two trials were homogeneous, so data for the trials were combined for analysis; however, variances associated with fresh weight of whole plants were not homogeneous between trials, so these data were analyzed independently. In two-way ANOVAs for both disease severity and plant weight, there was no significant interaction between isolate and inoculum concentration $(P>$ $0.05)$, so the main effects of concentration and isolate could be evaluated. Disease severity increased incrementally for concentrations between $1 \times 10^{3}$ and $1 \times 10^{7}$ conidia per $\mathrm{ml}$ and was greatest at the two highest concentrations, $1 \times 10^{6}$ and $1 \times 10^{7}$ conidia per $\mathrm{ml}$ (Fig. 3). There was a significant positive correlation $(P<0.001 ; r=$ 0.74 ) between disease severity and inoculum concentration. Likewise, plant weight decreased as inoculum concentration increased in both trials. In trial 1, plant weight was least at inoculum concentrations of $1 \times 10^{6}$ and $1 \times 10^{7}$ conidia per $\mathrm{ml}$, and in trial 2 , plant weight was least at concentrations between $1 \times 10^{5}$ and $1 \times 10^{7}$ conidia per ml (Fig. 3). In analyses of disease severity and plant weight, isolate F12 was significantly $(P<0.001)$ more virulent than isolate F46.

Variation in virulence among isolates of Fusarium spp. In the experiments to evaluate relative virulence among isolates of the three predominant species of Fusarium recovered from symptomatic plants, variances associated with both disease severity and weights of plants and plant parts in two independent trials were homogeneous, so data for the trials were combined for analysis. In the first experiment, 13 isolates of Fusarium sp. from nursery A were compared. These isolates varied significantly $(P<0.001)$ in both the severity of the disease they caused and in the effect they had on fresh weight of inoculated plants (Fig. 4). Disease severity ratings on plants inoculated with the 13 isolates ranged from 2.3 to 3.9 , and all of these ratings were significantly greater than that on the plants in the noninoculated control treatment. Eleven of the 13 isolates significantly reduced the weight of inoculated hosta plants compared with the noninoculated control plants. There was a significant $(P<0.001)$ but low negative correlation $(r=-0.31)$ between disease severity and plant weight. In the second experiment, 13 additional isolates of Fusarium sp. from nurseries C and D were evaluated and compared. These data were similar to and corroborate those in the first experiment so they are not presented here. For these 13 isolates, disease severity ratings ranged from 2.0 to 3.0 , varied significantly $(P<0.001)$, and were significantly $(P=0.05)$ greater than the severity rating (which was zero) on the noninoculated control plants. These isolates did not reduce the fresh weight of whole plants significantly $(P=0.261)$, but they did affect shoot fresh weight significantly $(P=$ 0.051). All isolates except one reduced shoot weight compared with the control treatment.

In the third experiment, five isolates evaluated and compared. Isolates of both species had less deleterious effect on hosta plants than isolates of Fusarium sp. Isolates within a species and among the two species varied in virulence (Fig. 5). Compared with the control treatment, only three isolates-one of $F$. solani (F62) and two of F. oxysporum (F51, F73)-had signifieach of $F$. solani and $F$. oxysporum were

cantly greater disease severity ratings, and five isolates-two of $F$. solani $(\mathrm{F} 45, \mathrm{~F} 70)$ and three of $F$. oxysporum (F51, F53, F73)_significantly reduced plant fresh weight.

\section{DISCUSSION}

F. solani, F. oxysporum, and Fusarium sp.-a unique, undescribed species of Fusarium-frequently were recovered from the vascular tissue of the roots and crowns of hosta plants with typical root and crown rot symptoms. All three species were proven to be pathogenic to hostas and were capable of causing Fusarium root and crown rot symptoms to some degree. However, Fusarium sp. was the only species that consistently caused symptoms typical of those observed in the field, had the greatest deleterious effect on plant growth, and therefore is considered the primary causal agent of this disease. The identity of this fungus has been investigated thoroughly at the Fusarium Research Center at
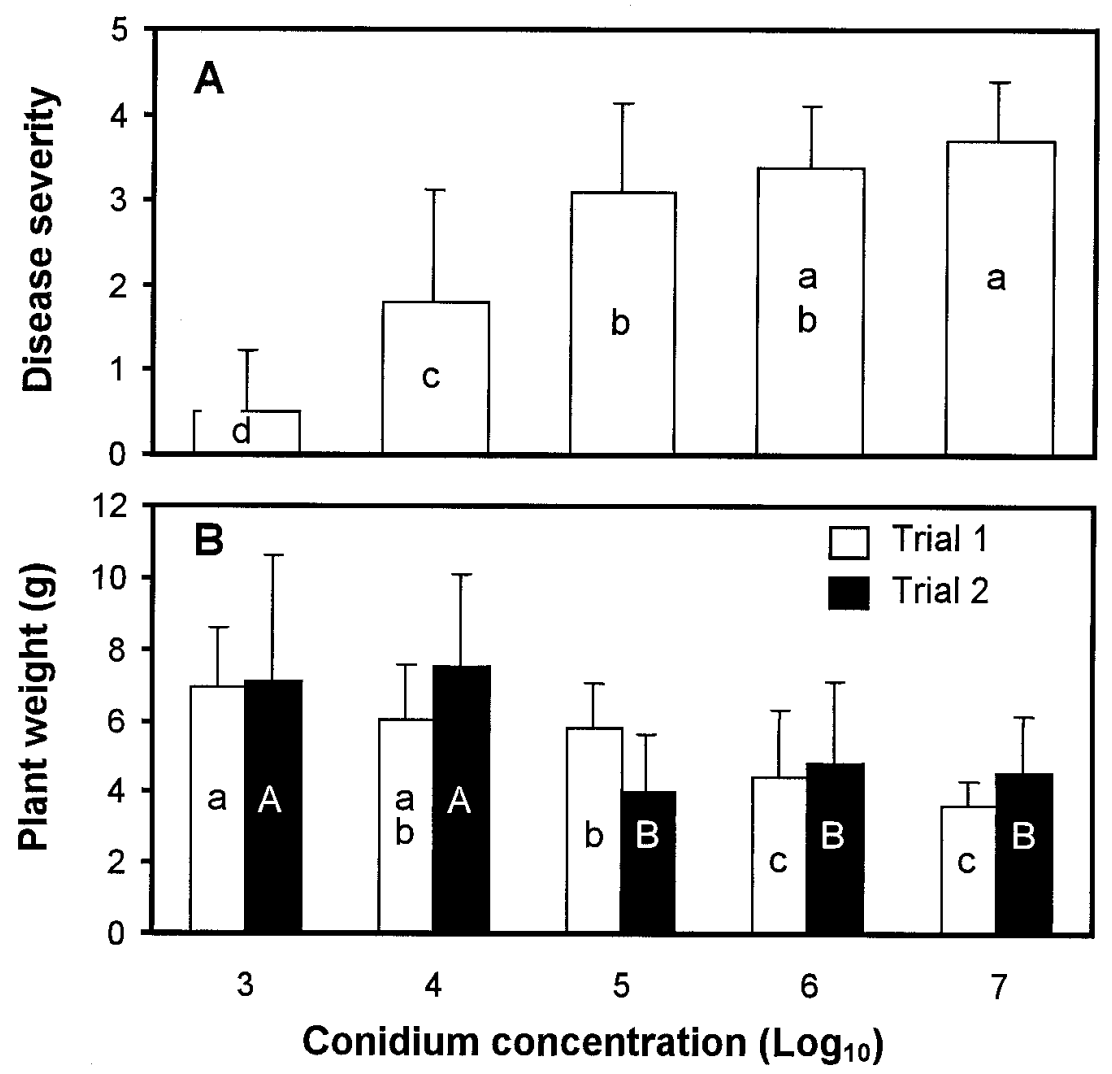

Fig. 3. Effect of concentration of conidia of Fusarium sp. on development of root and crown rot on wounded Hosta 'Francee' plants after 5 weeks at 20 to $22^{\circ} \mathrm{C}$ in a growth chamber. Two isolates and five concentrations were used, and two trials were conducted. In two-way analyses of variance, isolate $\times$ concentration interactions were not significant, so data for isolates were combined to evaluate the effects of concentration. (A) Disease severity was based on symptom development in the roots and crown and used a scale of 0 to 5: $0=$ no discoloration, $1=$ slight discoloration of vascular tissue in roots, $2=$ extensive discoloration of vascular tissue in roots, $3=$ slight discoloration of vascular tissue and cortex in the crown, $4=$ extensive discoloration of vascular tissue and cortex in the crown, and $5=$ crown completely necrotic. Bars are means of 32 observations ( 2 isolates $\times 8$ replicates $\times 2$ trials); bars without a letter in common are significantly different based on Fisher's protected least significant difference (LSD; $P=0.05$ ); $\mathrm{LSD}=0.40$. (B) Plant fresh weight is reported for each trial separately because the variance between trials was not homogeneous. For each trial, bars are means of 16 observations ( 2 isolates $\times 8$ replicates), and those without a letter in common are significantly different based on Fisher's protected LSD $(P=0.05) ; \operatorname{LSD}=0.97$ in trial 1 and $\operatorname{LSD}=1.56$ in trial 2 . Error bars are standard deviations. 
Pennsylvania State University; Fusarium sp. is believed to be a species that has not been described previously and tentatively has been named Fusarium hostae by D. M. Geiser and J. Juba (D. M. Geiser, personal communication).

$F$. solani and $F$. oxysporum appear to be only weak pathogens of hosta. F. oxysporum was recovered infrequently from symptomatic plants and does not appear to cause a serious problem in hosta production. On the other hand, $F$. solani was the species recovered most frequently from diseased plants and likely plays a significant role in Fusarium root and crown rot. The possibility that multiple species of Fusarium interact synergistically in a disease complex was not explored in this study but may exist because more than one species frequently was isolated from the same plant.

$F$. solani and $F$. oxysporum were recovered consistently from both roots and crowns of diseased hosta plants, but Fusarium sp. was recovered only from crown tissues of diseased plants. In previ- ous studies, microscopic examination has indicated that root diseases usually are initiated with the colonization and penetration of roots, with subsequent growth of the pathogen into the crown (26). The absence of Fusarium sp. in root tissues in our study is interesting. It may be that recovery was masked by the presence of $F$. solani, which often was found in the same plant specimen. $F$. solani has been shown to enter plants as a secondary invader or endophyte $(17,20)$. It also may be because sample size was insufficient. However, the recovery of Fusarium sp. from only crown tissues may be because this is the site of primary ingress and infection. This disease usually was observed on plants that recently had been cut back and dividedwhich is a method of vegetative propagation that involves splitting the crown of one plant into several pieces, each of which is transplanted to produce a new plant. If a knife used to divide a diseased plant becomes contaminated with the pathogen, it could transfer inoculum to wounded crowns during subsequent divi-
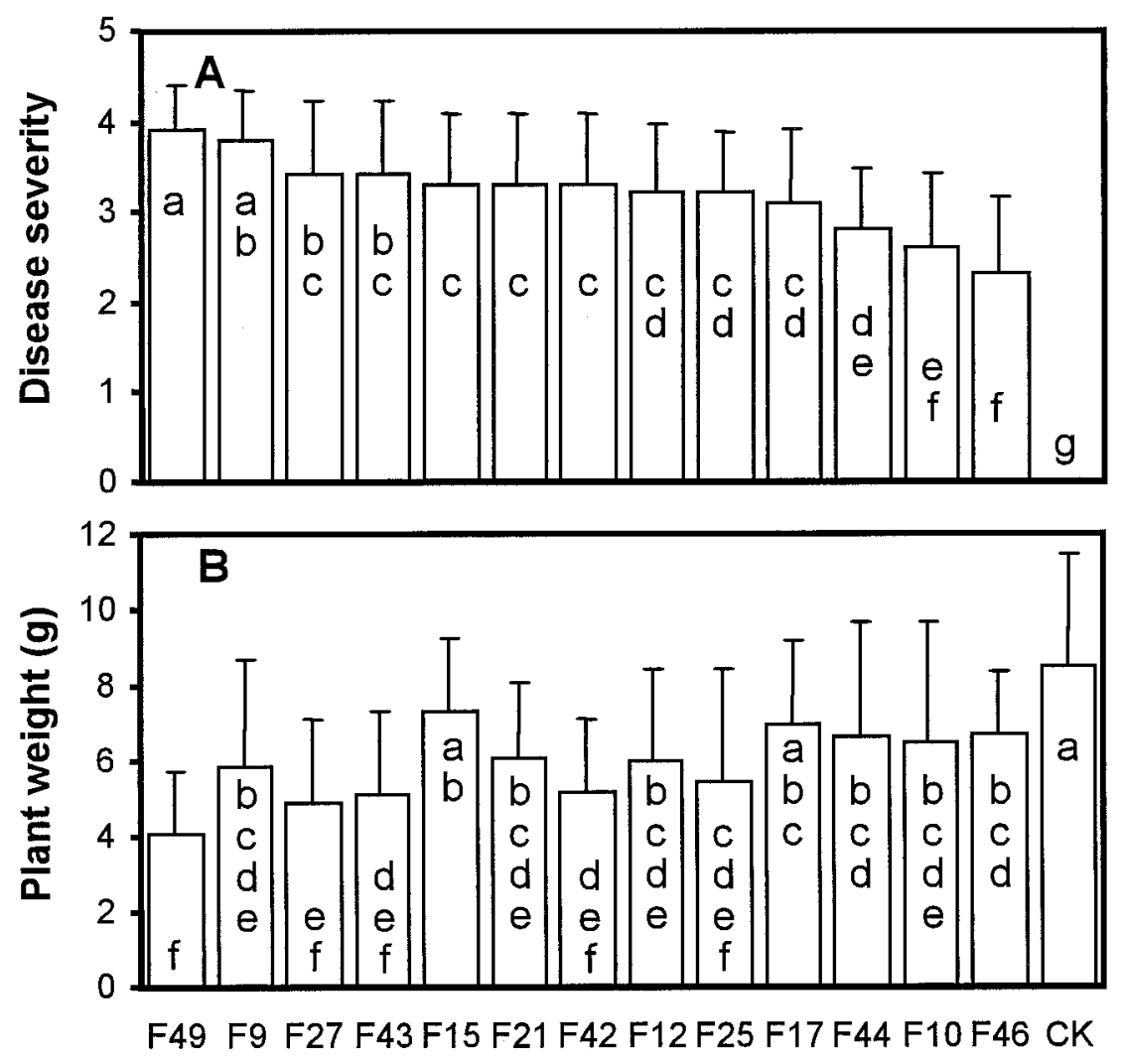

Isolates of Fusarium sp.

Fig. 4. Relative virulence of 13 isolates of Fusarium sp. and a noninoculated control (Con) on wounded Hosta 'Francee' plants after 5 weeks at 20 to $22^{\circ} \mathrm{C}$ in a growth chamber. (A) Disease severity was based on symptom development in the roots and crown and used a scale of 0 to 5: $0=$ no discoloration, 1 = slight discoloration of vascular tissue in roots, 2 = extensive discoloration of vascular tissue in roots, $3=$ slight discoloration of vascular tissue and cortex in the crown, $4=$ extensive discoloration of vascular tissue and cortex in the crown, and $5=$ crown completely necrotic. (B) Fresh weight of whole plants. In each graph, bars are means of 16 replicate plants in two trials, which were combined; bars without a letter in common are significantly different based on Fisher's protected least significant difference (LSD; $P=0.05$ ); $\mathrm{LSD}=0.498$ for disease severity; $\mathrm{LSD}=1.687$ for plant weight. Error bars are standard deviations.

sions. In support of this hypothesis, we consistently reproduced disease symptoms only when plants were wounded and wounds were exposed to inoculum. In addition, disease symptoms have been observed on plants inoculated with a scalpel contaminated with conidia of Fusarium sp. (B. Wang and S. N. Jeffers, unpublished). Consequently, primary infection may be occurring when plants are divided for vegetative propagation; therefore, sanitation during this process could be very important in limiting the spread of $\mathrm{Fu}$ sarium root and crown rot.

Hosta is not listed as a host of any species of Fusarium in the host index prepared by Farr et al. (10). A search of the literature and online databases failed to reveal any citations or references for Fusarium spp. associated with hosta or plantain lily. Previously, there has been only a brief mention of leaf yellowing and crown rot of hosta attributed to $F$. oxysporum (29), but no documentation or reference was supplied to support this occurrence. Therefore, this is the first documented report of Fusarium root and crown rot of hosta.

Although Fusarium root and crown rot has not been reported previously, we do not believe the occurrence is new. The disease was found at five of six large, wholesale nurseries where hostas were produced in containers. In addition, Fusarium root and crown rot was found on plants from 11 different cultivars-which came from two of the predominant taxa of Hosta used as landscape plants, $H$. 'Fortunei' and $H$. sieboldiana. Therefore, we suspect the disease occurs wherever hostas are produced in containers in large quantities. Because the pathogens may be disseminated when plants are divided, nurseries that routinely practice this method of vegetative propagation may be more likely to encounter Fusarium root and crown rot. This disease may have reached noticeable levels because of increased production of hostas at ornamental crop nurseries in recent years and current production practices at these nurseries (i.e., growing large quantities of plants that are genetically similar in close proximity, using overhead irrigation, propagating vegetatively, etc.). The primary source of inoculum for the disease has not been identified yet.

Artificial inoculation under controlled conditions is the primary means to determine pathogenicity of species and virulence of isolates and to evaluate susceptibility of host plants. Several methods have been utilized, with varying success, to inoculate plants with Fusarium spp. $(8,19)$. The colonized oat seed technique has been used commonly in studying the sudden death syndrome of soybean caused by $F$. solani $(21,30)$. Inoculation by pipetting conidium suspensions into soil around plants often has been employed for studying root and crown rot of tomato caused by F. oxysporum (13). However, both methods 
were ineffective for inoculating hosta plants growing in nursery container mix; neither method resulted in measurable regardless of the species of Fusarium involved. The reasons for this probably are complex since interactions between a host and a soilborne fungus can be influenced by many factors - particularly edaphic factors. In previous studies, diseases caused by soilborne fungi became less severe in coarse-textured, well-drained, and lowcompacted soils $(18,23,32)$.

Inoculation by dipping roots into a conidium suspension has been used effectively to study vascular wilt of cotton caused by F. oxysporum $(24,26)$. Likewise, it was the most effective method for inoculating wounded hosta plants with Fusarium spp. Direct exposure of fresh wounds and the entire root system to inoculum probably was responsible, at least in part, for the success of this inoculation method. In previous reports, it has been shown that wounding roots can disrupt physical defense barriers in plants, accelerate the colonization and penetration of the roots, disease symptoms in our experiments,

and increase the incidence and severity of root diseases caused by Fusarium spp. $(6,30)$.

The direct influence of inoculum concentration on the development of Fusarium root and/or crown rots has been reported for several pathosystems $(2,13,27)$. Likewise, our results showed that the severity of root and crown rot of hosta was significantly enhanced by increasing conidium concentration over the range of $1 \times 10^{3}$ to 1 $\times 10^{7}$ conidia per ml. This is consistent with a previous observation that the number of infective propagules on root surfaces is proportional to the levels of inoculum used (26). It is important to choose a reasonable inoculum concentration in pathogenicity tests so that the virulence of isolates or the susceptibility of host plants will not be masked by extraordinarily low or high inoculum levels. The concentration of $1 \times 10^{6}$ conidia per $\mathrm{ml}$ was used in our study and is recommended for work in the future because it consistently resulted in disease development.

There are many physiological races or biotypes of Fusarium spp. (3). In the pres-
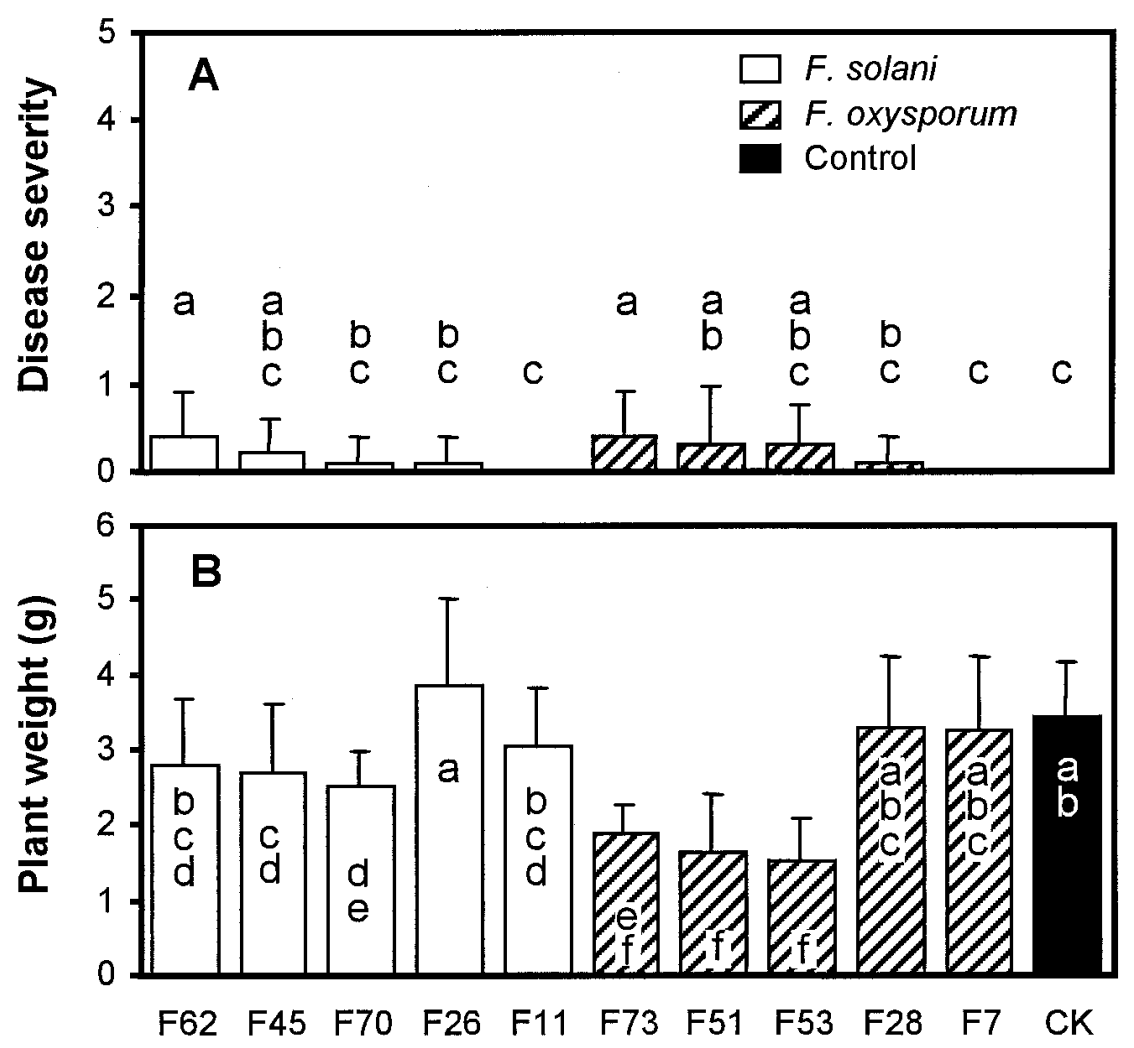

Isolates of F. solani and F. oxysporum

Fig. 5. Relative virulence of five isolates each of Fusarium solani and F. oxysporum and a noninoculated control (Con) on wounded Hosta 'Francee' plants after 5 weeks at 20 to $22^{\circ} \mathrm{C}$ in a growth room. (A) Disease severity was based on symptom development in the roots and crown and used a scale of 0 to 5: $0=$ no discoloration, $1=$ slight discoloration of vascular tissue in roots, $2=$ extensive discoloration of vascular tissue in roots, $3=$ slight discoloration of vascular tissue and cortex in the crown, $4=$ extensive discoloration of vascular tissue and cortex in the crown, and $5=$ crown completely necrotic. (B) Fresh weight of whole plants. In each graph, bars are means of 12 replicate plants in two trials, which were combined; bars without a letter in common are significantly different based on Fisher's protected least significant difference (LSD; $P=0.05$ ); LSD $=0.305$ for disease severity; LSD $=0.659$ for plant weight. Error bars are standard deviations. ent study, variation in virulence was observed among isolates of Fusarium sp., $F$. solani, and $F$. oxysporum. All 26 isolates of Fusarium sp. tested in two experiments were virulent to some degree on inoculated plants; however, only some of the isolates tested of $F$. solani and $F$. oxysporum were virulent on $H$. 'Francee' plants in our trials. Therefore, future research on this disease should take advantage of this information when experiments are designed-particularly studies on cultivar susceptibility and host range.

In the current study, disease severity ratings did not always correspond well to plant weights. Similar situations have been reported for other root rot diseases $(5,14,27)$. Two of the most critical factors for determining the influence of root disease on plant growth are the extent or degree of symptom development and the time it takes for these symptoms to develop. In our experiments, data were collected 5 weeks after inoculation. This period of time apparently was enough for the expression of disease symptoms in roots and crowns of infected plants, but it may have been insufficient for plant growth to be affected measurably. Alternatively, plants in our experiments differed somewhat in size at the onset of experiments even though they were grown from asexually propagated tissue culture plugs. Therefore, changes in plant growth caused by the disease over a 5-week period may have been masked or confounded by initial differences in plant size. In future experiments, the influence of initial differences in plant size could be minimized by using an analysis of covariance, by increasing the number of replicates per treatment, or by growing plants for a longer period before collecting data. Previously, one report suggested that changes in leaf area are the most sensitive indicator of plant stress caused by root diseases (27); more research is needed to determine a precise and reliable index for the influence of root disease on plant growth.

In summary, we demonstrated for the first time that root and crown rot of hosta is caused primarily by an undescribed species of Fusarium, designated here as Fusarium sp., which is morphologically similar to $F$. oxysporum and $F$. redolens. $F$. solani and $F$. oxysporum also may be involved in this disease but to a lesser extent. An inoculum concentration and a reliable inoculation method for reproducing the disease under experimental conditions were identified. Currently, we are investigating cultural practices that affect disease development and strategies for disease management.

\section{ACKNOWLEDGMENTS}

We thank H. A. Poole and Fafard, Inc., for providing container mixes; M. Rinck and Agri-Starts III, Inc., for providing hosta plants; D. M. Geiser, J. Juba, and the Fusarium Research Center for identifying isolates of Fusarium spp.; D. H. Lewis 
for photographic services; and W. M. Dowler and L. W. Baxter, Jr., for reviewing the manuscript.

\section{LITERATURE CITED}

1. Berkenkamp, B., Folkins, L., and Meeres, J. 1972. Crown and root rot of birdsfoot trefoil in Alberta. Can. Plant Dis. Surv. 52:1-3.

2. Bhatti, M. A., and Kraft, J. M. 1992. Effects of inoculum density and temperature on root rot and wilt of chickpea. Plant Dis. 76:50-54.

3. Booth, C. 1977. The Genus Fusarium. Commonwealth Agricultural Bureau, Farnham Royal, Bucks, England.

4. Burgess, L. W., Wearing, A. H., and Toussoun, T. A. 1975. Surveys of fusaria [Fusarium roseum] associated with crown rot of wheat in eastern Australia. Aust. J. Agric. Res. 26:791-799.

5. Burke, D. W., and Barker, A. W. 1966. Importance of lateral roots in Fusarium root rot of beans. Phytopathology 56:292-294.

6. Chi, C. C., Childers, W. R., and Hanson, E. W. 1964. Penetration and subsequent development of three Fusarium species in alfalfa and red clover. Phytopathology 54:434-437.

7. Correll, J. C., Puhalla, J. E., and Schneider, R. W. 1986. Identification of Fusarium oxysporum f. sp. apii on the basis of colony size, virulence, and vegetative compatibility. Phytopathology 76:396-400.

8. Dodman, R. L., and Wildermuth, G. B. 1987. Inoculation methods for assessing resistance in wheat to crown rot caused by Fusarium graminearum Group 1. Aust. J. Agric. Res. 38:473-486

9. Evans, T. A., and Stephens, C. T. 1989. Increased susceptibility to Fusarium crown and root rot in virus-infected asparagus. Phytopathology 79:253-258.

10. Farr, D. F., Bills, G. F., Chamuris, C. P., and Rossman, A. Y. 1989. Fungi on Plants and Plant Products in the United States. American Phytopathological Society, St. Paul, MN.

11. Fisher, N. L., Burgess, L. W., Toussoun, T. A., and Nelson, P. E. 1982. Carnation leaves as a substrate and for preserving cultures of Fusarium species. Phytopathology 72:151153.

12. Gamliel, A., Katan, T., Yunis, H., and Katan, J. 1996. Fusarium wilt and crown rot of sweet basil: Involvement of soilborne and airborne inoculum. Phytopathology 86:56-62.

13. Hartman, J. R., and Fletcher, J. T. 1991 Fusarium crown and root rot of tomatoes in the UK. Plant Pathol. 40:85-92.

14. Harveson, R. M., and Rush, C. M. 1998. Characterization of Fusarium root rot isolates from sugar beet by growth and virulence at different temperatures and irrigation regimes. Plant Dis. 82:1039-1042.

15. Hwang, S. F., Berg, B. P., Howard, R. J., and McAndrew, D. W. 1992. Screening of sainfoin cultivars and lines for yield, winter hardiness and resistance to fusarium crown and root rot in east central Alberta. Can. Plant Dis. Surv. 72:107-109.

16. Hwang, S. F., Howard, R. J., and Moskaluk, E. 1989. Crown and root rot of alfalfa in southern Alberta. Can. Plant Dis. Surv. 69:9-11.

17. Kalc Wright, G. F., Say, M., Pascoe, L. G., and Guest, D. I. 1997. Incidence and symptoms of Fusarium diseases of carnations in Victoria. Aust. Plant Pathol. 26:44-53.

18. King, C. J., and Presley, J. T. 1942. A root rot of cotton caused by Thielaviopsis basicola. Phytopathology 32:752-761.

19. Latin, R. X., and Snell, S. T. 1986. Comparison of methods for inoculation of muskmelon with Fusarium oxysporum f. sp. melonis. Plant Dis. 70:297-300.

20. Leslie, J. F., Pearson, C. A. S., Nelson, P. E., and Toussoun, T. A. 1990. Fusarium spp. from corn, sorghum, and soybean fields in the central and eastern United States. Phytopathology 80:343-350.

21. Lim, S. M. 1991. A technique for inoculating soybeans in the greenhouse with Fusarium solani. (Abstr.) Phytopathology 81:1238.

22. Lockhart, B. E. L., and Currier, S. 1996. Viruses occurring in Hosta spp. in the USA.
Acta. Hortic. 432:62-67.

23. Lockwood, J. L., Yoder, D. L., and Smith, N. A. 1970. Thielaviopsis basicola root rot of soybeans in Michigan. Plant Dis. Rep. 54:849-850.

24. Miller, D. A., and Cooper, W. E. 1967. Greenhouse technique for studying Fusarium wilt of cotton. Crop Sci. 7:75-76.

25. Nelson, P. E., Toussoun, T. A., and Marasas, W. F. O. 1983. Fusarium Species: An Illustrated Manual for Identification. Pennsylvania State University, University Park.

26. Rodriguez-Galvez, E., and Mendgen, K. 1995. The infection process of Fusarium oxysporum in cotton root tips. Protoplasma 189:61-72.

27. Rush, C. M., and Kraft, J. M. 1986. Effects of inoculum density and placement on Fusarium root rot of peas. Phytopathology 76:1325 1329.

28. Scardaci, S. C., and Webster, R. K. 1982. Common root rot of cereals in California Plant Dis. 66:31-34.

29. Schmid, W. G. 1991. The Genus Hosta. Timber Press, Portland, OR.

30. Stephens, P. A., Nickell, C. D., Moots, C. K. and Lim, S. M. 1993. Relationship between field and greenhouse reactions of soybean to Fusarium solani. Plant Dis. 77:163-166.

31. Stutz, J. C., Leath, K. T., and Kendall, W. A 1985. Wound-related modifications of penetration, development, and root rot by Fusarium roseum in forage legumes. Phytopathology 75:920-924.

32. Tu, J. C., and Tan, C. S. 1991. Effect of soil compaction on growth, yield and root rots of white beans in clay loam and sandy loam soil. Soil Biol. Biochem. 23:233-238.

33. Wang, B., and Jeffers, S. N. 1999. Fusarium root and crown rot of hosta. Proc. Southern Nursery Assoc. Res. Conf. 44:244-246.

34. Wang, B., and Jeffers, S. N. 1999. Incidence of Fusarium spp. in diseased roots and crowns of hosta plants. (Abstr.) Phytopathology $89:$ : 82 . 